After a clear summary of the physiological changes in blood coagulation that occur in pregnancy the first part deals with deep vein thrombosis and pulmonary embolism, both important causes of morbidity, and even mortality. Their management and prevention are still poorly understood by many clinicians. The second part deals with the problems of lack of coagulation. Again, clinical awareness, particularly among junior staff, is limited to requesting a range of tests, often of doubtful importance, in any woman with vaginal bleeding in pregnancy. As Dr Letsky points out, for many of these women the tests that are done are inappropriate, whereas for others they may even give dangerously misleading answers.

The book is concise, free of jargon, and a pleasure to read. It avoids lists of facts, but gives a simple, personal approach. Pulmonary embolism is still a leading cause of maternal mortality, and although haemorrhage is less important as a direct cause of maternal mortality, Dr Letsky emphasises that careful management can help to avoid an excessive number of blood transfusions. Some acquired disorders of coagulation can now be detected antenatally, and the realisation of the link between coagulation disorders and recurrent early loss in pregnancy and intrauterine growth retardation is growing.

Unfortunately, there are more typographical errors than there should be. At best some are irritating, but some are serious. On page 32 there is a discussion on the dangers of venography. Much is made of the relative superiority of Amupaque (metrinamide), but the letter quoted as a reference actually discusses Ampipaque (metrizamide). Many authorities consider that metrizamide has been superseded by newer, less irritant agents. In the same paragraph there is a reference to a paper reading from page 728-724 in the Lancet. On page 120 the first line has been left off a paragraph. There is possibly one error. On page 9 there is the comment that treatment with streptokinase results in an increase in plasminogen. This happens only after fibrinolysis has been completed, with the rise occurring as a result of the treatment being successful, not as a result of the streptokinase per se.

This is a good book, which should be read by everyone who is studying for the membership examination of the Royal College of Obstetricians and Gynaecologists and be in the pocket of everyone who deals with, however infrequently, women with coagulation problems in pregnancy.

PeTER BRomWich

\section{Pregnancy and drugs}

Ellis Horwood Series. Biochemistry and Pharmacology in Medicine and Neurosciences. "The Biochemical Effects of Drugs in Pregnancy." Vol 1. "Drugs Active on the Nervous, Cardiovascular, and Haemopoietic Systems." A Onnis, P Grella. Series editor J de Belleroche. (P 411 ; £45.) Ellis Horwood. Distributed by John Wiley and Sons. 1984.

Since the thalidomide tragedy, drug prescribing in pregnancy has been limited - at least in theory. But pregnant women may need drugs for good medical reasons, and the results of several surveys have shown that they take a wide variety of medication that is prescribed by their physicians or bought across the counter. Nevertheless, we remain surprisingly ignorant of the effects of many drugs, including those commonly prescribed, on the course of gestation and development of the conceptus.

The title of this book arouses interest and at first glance it seems to fill a gap. The introduction, in which the authors briefly describe aspects of drug action in pregnancy in addition to transplacental passage and teratogenic influence of drugs, offers further promise. But the title belies the contents. Each chapter follows the conventional line, the effect of drugs in pregnancy being considered essentially in relation to the extent of their passage across the placental barrier and teratogenicity. From this view it provides a good summary of what is known in different species, particularly rodents, and indicates the potential adverse clinical effects of drugs in pregnancy, where these are known.
The influence of drugs on metabolic processes in the placenta and consequently on fetal development is, however, rarely mentioned. This book typifies the late Peter Beaconsfield's description: "Placenta-a neglected experimental animal." Why, as he so often emphasised, we do not use this tissue for its manifold potential as a model for cell replication, immunological and metabolic processes, and, above all, for drug testing in pregnancy is hard to understand.

Among the several thousand references (unfortunately without titles) few are of fundamental scientific interest. The high price of the book also puts it beyond the pocket of the young research worker who might need it in the laboratory, and since by its nature it will require updating and revision it is a pity that a paperback version is not available.

JEAN GINSBURG

\section{In brief . . .}

Looking Forward . . . a Guidebook for the Laryngectomee (Georg Thieme, DM 29, paperback) is cheerful, no hint of tragedy intrudes, and the advice given on stoma care and the nature and extent of the operation is fulsome and helpful. It appears to be directed to well motivated patients in the prime of life, such as those who are willing and able to care for their stoma or tubing and those who have an insight into the mechanism of a laryngectomy, rather than to those who are fearful, uninformed, or elderly. No guidance is given to the person who has had a partial laryngectomy or a pharyngolaryngectomy, or to those who use the various fistula techniques and prostheses that are currently undergoing trials for the restoration of speech. The equipment shown, such as tracheostomy tubes, is not standard in the United Kingdom. The book may be recommended carefully to some laryngectomees in the UK. It would not unhinge a patient who was about to face the operation, but it might mystify him.

\section{Contributors}

$\mathrm{S} \mathrm{T}$ Holgate is a reader in medicine at the University of Southampton.

ANDREW P READ is a senior lecturer in medical genetics at the University of Manchester, Manchester.

P J MADDison is a consultant at the Royal National Hospital for Rheumatic Diseases, Bath.

GLYN EVANS is a lecturer in orthopaedics at the University of Southampton, Southampton.

$\mathrm{R} \mathrm{H}$ Champion is a consultant dermatologist at Addenbrooke's Hospital, Cambridge.

PETER Bromwich is a clinical lecturer in obstetrics and gynaecology at the Nuffield Department of Obstetrics and Gynaecology, University of Oxford.

JEAN GINSBURG is a senior lecturer in endocrinology at the Royal Free Hospital Medical School, London.

\section{Correction}

ADIS Health Science Press publications are distributed by John Wright and Sons, not by John Wiley and Sons as stated in the review "Dermatology à deux" (16 March, p 850) and in the list of new titles (23 February, p 633). 